\title{
移动学习模式在高职院校艺术设计专业素质育化教育中的实 践研究
}

\author{
刘韬 崔军林 毛锡㭉 王灵 \\ 苏州工艺美术职业技术学院 \\ DOI:10.32629/mef.v2i8.193
}

[摘 要] 移动学习模式以高职院校的无线互联、云计算和云存储技术为发展基础,属于智慧校园建设的组成部分。本文从高 职艺术设计专业学生素质育化课程的需求出发, 结合高职艺术设计专业的特点, 基于学生的学情特征、学习习惯特征、学习心 理特征来进行移动学习资源和平台建设,构建高职素质育化课程的移动学习教学模式的理论体系,探索移动学习资源和平台建 设的路径, 改进教学评价机制, 建立 “资源一学习一教学一评价一优化升级” 的移动学习循环系统, 进一步促进高职艺术设计专 业素质育化课程的信息化水平。

[关键词] 移动学习; 素质育化; 艺术设计

\section{Practical Research on Mobile Learning Mode in the Quality Education of Art Design Major in Higher Vocational Colleges}

Liu Tao, Cui Junlin, Mao Xirong, Wang Ling

Suzhou Art\&Design Technology Institute

[Abstract] The mobile learning model is based on the wireless interconnection, cloud computing and cloud storage technologies of higher vocational colleges, and is part of the construction of smart campus. This paper starts from the needs of the quality education curriculum for art design majors in higher vocational colleges, combines the characteristics of higher vocational art design majors, and builds mobile learning resources and platforms based on students' academic characteristics, learning habits and learning psychological characteristics, constructs a theoretical system of mobile learning teaching mode for higher vocational quality education curriculum, explores the path of mobile learning resources and platform construction, improving the teaching evaluation mechanism, and establishing a mobile learning circulation system of "resources-learning-teaching-evaluation-optimization and upgrading" to further promote the information level of the quality education curriculum for art design majors in higher vocational colleges.

[Key words] mobile learning; quality education; art design

随着互联网 + 、移动智慧产品以及大数据技术的飞速发 展, 在教育领域不断掀起新的变革浪潮, 传统的素质教育模 式同样面临着新的机遇和挑战。每一次新技术的出现都能给 教育领域带来新的学习方法及学习体验, 互联网与移动智慧
产品的发展, 使得互联网的应用范围得到极大延伸, 学习活 动从PC扩展到移动智能终端, 于是就产生了一种新的学习模 式一移动学习 (M-Learning)。移动学习使得学习者能够随 时随地学习, 不再受时间、空间的限制。移动学习在自主性、

\section{[参考文献]}

[1]田胜.大学生思想政治教育协同育人机制的构建一 一以武汉工商学院为例 [J]. 文教资料,2016(21):129-131.

[2]盛冬梅.把思想政治工作贯穿教育教学全过程[N].吉 林日报,2019-09-02.

[3] 习近平.在北京大学师生座谈会上的讲话 $[N]$. 人民日 报,2018-05-03.

[4]可近.在全国高校思想政治工作会议上强调：把思 想政治工作贯穿教育教学全过程 开创我国高等教育事业发 展新局面[N].人民日报,2016-12-09.
[5]陈荣武.高校组织育人协同体系建构及其功能实现 [J].思想理论教育,2018(3):95-99.

[6]郑俊玲.高校大思政育人模式分析一一兼论专业教师与 思政工作者协同育人问题[J].探讨与研究,2018(2):157-158.

[7]余江涛.王文起.专业教师实践 “课程思政”的逻辑及 其要领——以理工科课程为例 [J]. 学校党建与思想教 育,2018(1):64-66.

作者简介:

石玉枝(1991--), 女, 山东邹平人, 汉族, 硕士, 助教, 研究方 向：高等教育。 
便捷性、灵活性、互动性及延续性等多个方面比传统的学习 模式更具优势。但由于目前该研究主要集中在 “移动学习” 的理论推介等方面, 与国外相比, 移动学习基础理论研究还 相当薄弱, 尤其将高职院校艺术设计专业的素质育化教育与 移动学习模式结合的实证研究较少。而高职院校素质教育理 念与移动学习实践不仅对于丰富教育基本价值观, 发展教育 改革新内容具有深刻的理论价值; 而且对于我国当前的高职 院校人才培养, 尤其是艺术设计专业教学改革实践也具有较 高的现实意义。

\section{1 关于移动学习的界定和素质育化的相关研究}

1.1 移动学习的概念厘定与特点

在移动学习的基础理论研究中, 往往将非正式学习、远 程教育等宽泛的概念引入到移动学习的概念中。在本文中更 倾向于将移动学习模式定义为基于移动通讯技术发展, 而形 成的包含移动学习硬件环境、移动设备、资源平台、学习个 体、评价系统等因素的学习系统。在高职教育领域, 移动学 习模式是能够充分运用信息化网络技术, 实现教育信息化的 重要手段, 也是高职院校构建智慧校园, 促进教学改革的有 效方法。

移动学习模式得以推广的基础在于移动通信基础设施 的完善, 学习资源和知识体系的建设, 以及学习服务体系的 完善。在高职校园内, 主要表现在校内无线网络的覆盖, 校内 及网络课程的开发和资源整合, 学校教师对于移动学习模式 的引导等。

\section{2素质育化的研究现状}

何国清 (2009) 首次提出 “素质育化” 的概念, 指出 “素质 育化” 相对于 “素质教育” 更强调学生的主体地位。“育化” 是 “育而化之”之意, 在 “育化” 的概念之下, 体现的是教师 主导之下的学生的主体地位。而在 “教育” 的概念之下体现 的是教者与学者之间的 “施” 与 “受” 的关系。因此, 素质育 化与移动学习模式在学生主体地位上是一致的。施教芳、马 华 (2010) 提出素质育化平台的搭建, 构建了素质育化实施平 台模块构成; 孙丽华 (2011) 提出了建设艺术院校素质育化”双 体系”格局的理论构想, 并阐述了建设的路径问题; 施教芳、 孙立新 (2012) 在素质育化体系中提出构建校企合作互动的 质量控制系统; 钱华 (2014) 在素质育化课程体系基础上结合 三维影视动画方向的跨专业应用课题展开研究; 沈杨 (2016) 从课程设置、课程形式、考核方式上对素质育化课程体系进 行了探索。

素质教育在我国已经推行10多年, 可传统的素质教育教 学形式、教学资源未能与教育信息化、大数据、智能化的发 展趋势相适应, 不能满足当前大学生的学习兴趣和习惯。在 学生学习过程中出现一个新词 “刷课”, 即课程在电脑上打 开, 人在做其他事情的情况。素质教育课程的学习效果和学 习监测、评价体系均有待与教育信息化的背景相融合从而进 一步完善。

\section{2 素质育化课程的特征与学习者学情分析}

素质育化课程的移动学习关键在于构建适应数字化学 习的学习环境, 在课程开展中形成以学习者为中心、基于移 动智慧终端自主学习、网络互动交流服务和数字化测评相结 合的学习新模式。需要从教学对象需求的角度切入移动学习, 并结合成熟的教育学理论完善移动学习的基础理论, 构建高 职素质育化课程的移动学习教学模式的理论体系。

高职艺术设计的学生具备大学生对新生事物接受度高, 接受速度快的特点, 但相对于本科阶段的学生往往存在学习 基础不稳定, 学习习惯自律性差等特点。结合高职艺术设计 专业的特点, 应该注重素质育化课程的知识性设计、情景化 设计、人性化设计和交互性设计。探索移动学习资源和平台 建设的路径, 改进素质教育教学评价机制, 建立 “资源一学习 一教学一评价一优化升级” 的移动学习循环系统。通过探索 移动学习的发生和发展规律, 根据高职艺术设计专业学生学 情特征和学习习惯, 要注重丰富素质育化课程的教学形式和 学习模式, 完善移动学习教学模式给学生提供更多的自主学 习空间, 满足不同的个性化学习需求。

\section{3 移动学习模式的构建和特点}

根据素质育化课程的特征和移动学习局限性、多样性、 个性化的特点, 移动学习模式的建构是包含移动学习硬件环 境、移动设备、资源平台、学习个体、评价系统等因素的学 习系统。其学习过程的核心板块应该包括平台架构、数据统 计、系统分析、教学资源推送与反馈、学习监督、评价反馈 等部分。

当前移动学习模式在高职院校教学应用中, 往往存在授 课比重科学性较低, 教学内容单调, 个性化程度不足, 依赖市 场学习平台等问题, 移动学习的课程内容与课堂内容衔接性 也往往较低。这些问题对于学生知识体系的形成常会造成困 难, 因此在移动学习模式的建构中还要注意一些问题。

\section{1 加强移动学习方式的引导}

移动学习模式是当前信息化教学应对移动通信技术大 发展, 学生学习习惯改变这种现状的一种新的教学形式, 作 为教学活动的引导者, 教师必须及时转变教学思想, 对教学 体系和内容进行调整使其适应新时代学生新的变化。首先要 重视移动学习模式的效果, 注重移动学习方式介入到日常教 学, 处理好课堂教学与移动教学的衔接关系, 合理设置移动 学习与课堂学习的比重。

3.2 学习平台的架构

移动学习的平台架构对支撑学习行为的发生、发展、反 馈等方面具有核心的作用, 基于网络问卷调研对高职院校学 生学情的分析, $41 \%$ 的学习者会觉得视觉疲劳而专注度下 降, 35. 9\%的学习者面对大量学习资料, 利用效率比较低。因 此, 学习平台的易用性和友好性是平台架构中应该注意的问 题。易用性的平台一般具有一下特征：（1）系统使用方式简 单, 操作过程能够符合人机交互的基本原则; (2)平台的系统 应该针对大学生的应用情境而提供适当的功能; (3) 平台上 丰富的教学资源和内容, 系统应该具有一定的导学作用; (4) 
接入平台的形式应该具有多样化和兼容性。

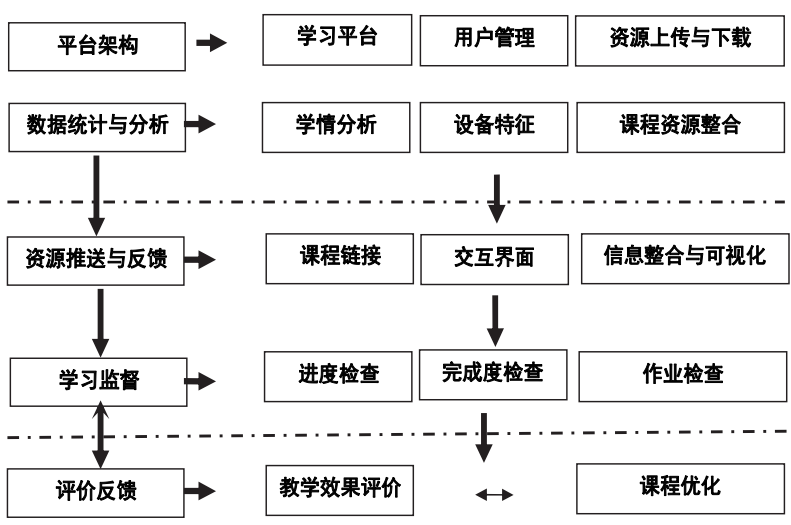

3.3 教学资源的设计整合

教学资源的整合与设计中要增强移动学习内容与课堂 教学内容的衔接性, 同时要适应移动学习时间碎片化、个性 化的特征。教学资源的设计和推送要以学生学情分析为基础, 确定资源推送的难易程度。同时学习资源应该按模块划分为 知识模块、案例模块和习题模块等, 学生按照学习进度循序 渐进, 通过汶览、下载、反馈等过程完成学习。

3. 4 学习过程监管与学习效果评价

在移动学习模式中, 教师无法在视线范围内管理学生 的学习进度和专注度, 因此学生可控性是解决问题的核心 点。针对这样的问题可以采用一些措施来解决：（1）在平台 架构过程中增加移动监管软件功能, 能够系统对学生学习情 况进行记录和可视化统计。对于未完成预定进度的情况, 教 师可以点对点进行提醒和分析原因。(2) 构建学习小组监督 机制, 形成学习小组内部互相监督促进学习的氛围。

在学习效果的评价上, 应构建多层次的学习效果评价体 系。美国著名学者Donald最先提出四层次评价模型, 将评价 划分为反应、学习、行为和结果四个部分。移动学习的效果
评价应该多元化的进行, 从参与者学习过程的情况进行反应 层的评价, 从学习者知识内容掌握的情况对其进行学习层评 价, 从学习者行为改变的角度进行行为层的评价, 最终, 结合 过程性评价和终结性评价做出结果层的评价。

\section{4 结语}

高职艺术设计专业素质育化课程所体现的教师引导之 下学生的主体地位, 与移动学习模式自主化、个性化的特征 是匹配的, 通过实施移动学习的教学实验, 依据试验数据探 索移动学习的发生、发展规律, 以此了解高职艺术设计专业 学生的学习需求和习惯, 将移动学习无缝嵌入参与者的学习 习惯, 并检验移动教学的模式、策略与评价体系的有效性。 高职院校素质教育理念与移动学习实践不仅对于丰富教育 基本价值观, 发展教育改革新内容具有深刻的理论价值, 对 于我国当前的高职院校人才培养, 尤其是艺术设计专业教学 改革实践也具有较高的现实意义。

\section{[参考文献]}

[1]何国清.素质育化育人理性化[J].涂州职业技术学院 学报,2009,8(04):43-46.

[2]沈杨.艺术设计职业教育中素质育化课程体系的建构 [J].绥化学院学报,2016,36(06):119-121.

[3]钱华.浅谈高职院素质育化课程的课题研究与实践 [J].艺术科技,2014,27(11):228.

\section{作者简介:}

刘韬(1979--), 男, 重庆云阳县人,汉族, 副教授, 硕士, 研究 方向：工业设计与设计教育研究。

\section{基金项目:}

江苏省教育厅高等学校哲学社会科学基金项目《移动学 习模式在高职院校艺术设计专业素质育化教育中的构建研 究》(项目编号 2017SJB1424)研究成果之一。 